\title{
Phosphorus sustains life
}

\author{
Zed Rengel • Fusuo Zhang
}

Received: 16 October 2011 / Accepted: 17 October 2011/Published online: 5 November 2011

(C) Springer Science+Business Media B.V. 2011

With a world population reaching 7 billion in 2011 and projected to increase up to $50 \%$ in the next 4 decades, coupled with expected increases in the living standards, agriculture is faced with a huge challenge to double the food production in that period, but on a shrinking area of farmland. This challenge needs to be met without harming the environment. With all that in mind, it is quite clear that management of phosphorus cycling in the soil-plant continuum becomes a critical issue, even if one accepts relatively optimistic estimates of the existing phosphate rock resources and rosy projections about yet undiscovered potential phosphate rock deposits made by the International Fertilizer Development Center (IFDC), estimating there are sufficient phosphate rock reserves for fertiliser production for the next 300-400 years (as opposed to recent warnings that the world will run out of phosphate rock in about $1 / 10$ of that time).

To address the importance of $\mathrm{P}$ in food production, the 4th International Symposium on Phosphorus

Responsible Editor: Hans Lambers.

Z. Rengel

School of Earth and Environment,

University of Western Australia,

Perth, Australia

F. Zhang $(\bowtie)$

College of Natural Resource and Environmental Sciences,

China Agricultural University,

Beijing, China

e-mail: zhangfs@cau.edu.cn
Cycling in the Soil-Plant Continuum titled "Phosphorus Sustains Life" was held in Beijing, China, 19-23 September 2010. It continued the series that started in Beijing (2000) followed by Perth, Australia (2003) and Uberlandia, Brazil (2006). The 4th Symposium continued to emphasise multidisciplinarity, providing a forum for exchange of ideas by soil and industrial chemists, agronomists, ecologists, plant physiologists, microbiologists, breeders, molecular biologists, environmental scientists, and others.

The symposium attracted 187 registered participants from 24 countries, and featured 181 abstracts and 140 posters. The symposium was organised around five themes covering phosphorus research from the molecular to the ecosystem levels:

(1) Phosphorus forms and availability in soil

(2) Plant acquisition and utilisation of phosphorus

(3) Genetics and molecular biology of phosphorus nutrition

(4) Phosphorus in agricultural, horticultural and forest production

(5) Phosphorus dynamics and environmental impact in natural and managed ecosystems

This Special Issue of Plant and Soil contains some of the papers presented at the 4th Phosphorus Symposium. Several papers deal with the soil-plantmicrobe interactions in the rhizosphere. Feng et al. present evidence that acidification of the rhizosphere enhances mineralisation of organic $\mathrm{P}$ in the maize 
rhizosphere. Richardson et al. review plant and microbial strategies to improve the amount of food produced per unit of $\mathrm{P}$ in agriculture, whereas Liao et al. concentrate on the enhancement of $\mathrm{P}$ acquisition by soybean plants inoculated with rhizobia. Various aspects of cell biology are covered in the paper by $\mathrm{Xu}$ et al. on how the root-cell plasma membrane proton pumps adjust to $\mathrm{P}$ deficiency. Soil chemistry as it influenced $\mathrm{P}$ accumulation in agricultural soil is covered by McLaughlin et al. Several papers dealt with $\mathrm{P}$ management in various farming systems (McIvor et al. on terms of tropical grazing systems; Weaver et al. on cropping and pasture systems; Zhang et al. on cropping systems in China). The last paper covers not just agricultural aspects of improving P-use efficiency, but also management of $\mathrm{P}$ for environmental protection. The environmental theme is fully explored in the final paper by Kleinman et al., providing the framework for ensuring $\mathrm{P}$ management that will protect quality of streams and other water bodies.
We would like to thank numerous reviewers who offered valuable comments and suggestions. Their dedication and knowledge helped to improve the papers. We would also like to thank the Natural Science Foundation of China and China Agricultural University for their financial and other support, which greatly contributed to the Symposium's success.

We hope this Special Issue of Plant and Soil will stimulate further research on various aspects of $\mathrm{P}$ cycling in the soil-water-plant continuum, with an added emphasis on animal and human nutrition as impacted by the quality of plant-based feed and food. Phosphorus cycling in natural and managed ecosystems requires concerted multidisciplinary efforts in generating the scientific knowledge and translating it into management actions. We are looking forward to new ideas to be presented at the 5 th International Symposium on Phosphorus Cycling in the Soil-Plant Continuum to be organised by Philippe Hinsinger in Montpellier, France in 2014. 